\title{
Fucoidan protects ARPE-19 cells from oxidative stress via normalization of reactive oxygen species generation through the $\mathrm{Ca}^{2+}$-dependent ERK signaling pathway
}

\author{
XIAOXIA LI ${ }^{1 *}$, HAIYAN ZHAO ${ }^{2 *}$, QINGFA WANG $^{3}$, HONGYAN LIANG $^{1,4}$ and XIAOFENG JIANG ${ }^{1,4}$ \\ ${ }^{1}$ Department of Clinical Biochemistry Laboratory, The Fourth Affiliated Hospital of Harbin Medical University, Harbin, \\ Heilongjiang 150001; ${ }^{2}$ Department of Ophthalmology, Central Hospital of Liaoyang City, Liaoyang, Liaoning 111000; \\ ${ }^{3}$ Department of Emergency, The First Affiliated Hospital of Jiamusi University, Jiamusi, Heilongjiang 154002; \\ ${ }^{4}$ Heilongjiang Province Key Laboratory of Molecular Imaging, Harbin, Heilongjiang 150001, P.R. China
}

Received March 19, 2014; Accepted December 12, 2014

DOI: $10.3892 / \mathrm{mmr} .2015 .3224$

\begin{abstract}
Diabetic retinopathy (DR) is a common complication of diabetes mellitus (DM) and it is the main cause of loss of vision. In previous years, interest in the biological activities of marine organisms has intensified. The effect of fucoidan from the seaweed Fucus vesiculosus on the molecular mechanisms of numerous diseases has been studied, while to date, its effect on DR was yet to be investigated. Therefore, the aim of the present study was to evaluate the role of fucoidan in DR. The human retinal pigment epithelial cell line ARPE-19 was exposed to high D-glucose in the presence or absence of fucoidan. Cell viability was monitored using MTT and lactate dehydrogenase assays. The intracellular reactive oxygen species (ROS) generation was measured using fluorescence spectrophotometry. Cell apoptosis was measured by flow cytometry using Annexin V-fluorescein isothiocyanate staining. $\mathrm{Ca}^{2+}$ influx was measured with a calcium imaging system and the activation of the extracellular signal-regulated kinase $(E R K)$ protein was evaluated using western blot analysis. The non-toxic fucoidan protected ARPE-19 cells from high glucose-induced cell death and normalized high glucose-induced generation of ROS. Fucoidan also inhibited high glucose-induced cell apoptosis, as well as the $\mathrm{Ca}^{2+}$ influx and ERK1/2 phosphorylation in ARPE-19 cells. Taken together, these findings indicated that fucoidan protects ARPE-19 cells against high glucose-induced oxidative damage via
\end{abstract}

Correspondence to: Dr Xiaofeng Jiang, Department of Clinical Biochemistry Laboratory, The Fourth Affiliated Hospital of Harbin Medical University, 37 Yiyuan, Nangang, Harbin, Heilongjiang 150001, P.R. China

E-mail: jiangxiaofeng12359@163.com

${ }^{*}$ Contributed equally

Key words: fucoidan, retinal pigment epithelium, reactive oxygen species, $\mathrm{Ca}^{2+}$ influx, extracellular signal-regulated kinase $1 / 2$ normalization of ROS generation through the $\mathrm{Ca}^{2+}$-dependent ERK signaling pathway.

\section{Introduction}

Diabetic retinopathy (DR) is a common complication of diabetes mellitus (DM) $(1,2)$. High glucose inflicts oxidative damage on cells of the retinal pigment epithelium (RPE) and causes pathological changes, which are responsible for the loss of vision associated with DR (3). Overproduction of reactive oxygen species (ROS) contributes to oxidative stress-induced cell injury (4). ROS may mediate RPE cell dysfunction and lead to hyperglycemic complications in diabetes (5). It has been reported that ROS generation is responsible for cell damage in cultured ARPE-19 cells (6) and that high glucose increases the generation of ROS (7); therefore, to protect the retina from oxidative damage, intracellular ROS production in RPE cells must be inhibited.

In previous years, research into the biological activities of marine organisms has intensified. The effect of fucoidan from the seaweed Fucus vesiculosus on the molecular mechanisms underlying numerous diseases has been investigated. It exhibits potent antioxidant activities and has effects on processes involved in cancer and inflammation $(8,9)$. Due to the potential of fucoidan as an anti-oxidant, anti-cancer and anti-inflammatory agent, it was the aim of the present study to determine the protective effect of fucoidan on DR. In the present study, the hypothesis that fucoidan protects ARPE-19 cells against high glucose-induced oxidative damage was assessed for the first time, to the best of our knowledge. The effect of fucoidan on high glucose-induced ROS generation, apoptosis, $\mathrm{Ca}^{2+}$ influx and extracellular signal regulated kinase (ERK1/2) phosphorylation in ARPE-19 cells was investigated. The observations of the present study indicated that fucoidan may represent novel therapeutic agent for the treatment of DR.

\section{Materials and methods}

ARPE-19 cell culture. The ARPE-19 cell line was purchased by the American Type Culture Collection (Manassas, VA, 
USA). ARPE-19 cells were cultured in Dulbecco's modified Eagle's medium/nutrient mixture F12 (DMEM/F12 medium; Life Technologies, Grand Island, NY, USA) with penicillin (final concentration, $100 \mathrm{U} / \mathrm{ml}$ )-streptomycin (final concentration, $100 \mu \mathrm{g} / \mathrm{ml}$ ) (Gibco-BRL, Grand Island, NY, USA) and $10 \%$ fetal bovine serum (Moregate Biotech Co., Ltd., Bulimba, Australia) at $37^{\circ} \mathrm{C}$ in a $5 \% \mathrm{CO}_{2}$ atmosphere. Fresh conditioned medium was added every third day and subcultures were digested every seventh to eighth day with $0.25 \%$ trypsin (Gibco-BRL).

Cytotoxicity offucoidan. Cell Titer $96^{\circledR}$ AQueous One Solution cell proliferation assay (Promega, Madison, WI, USA), which is an effective assay to demonstrate cytotoxicity, was used to determine the cytotoxicity of fucoidan. According to the manufacturer's instructions, ARPE-19 cells at a concentration of $2 \times 10^{4}$ cells/well were inoculated and incubated in 96-well plates with conditioned DMEM/F12 medium at $37^{\circ} \mathrm{C}$ under a $5 \% \mathrm{CO}_{2}$ atmosphere for 2 days. The ARPE-19 cells were treated with different concentrations of fucoidan $(0,1,10,100$ and $1,000 \mu \mathrm{g} / \mathrm{ml}$ ) for another $24 \mathrm{~h}$, followed by addition of $20 \mu$ l CellTiter $96^{\circledR}$ AQueous One Solution cell proliferation assay solution into all 96 wells. ARPE-19 cells were further incubated for $1 \mathrm{~h}$ and the absorbance at $490 \mathrm{~nm}$ was measured by an MTP-800 microplate reader (Corona Electric, Tokyo, Japan).

MTT assay. ARPE-19 cells were cultured at $37^{\circ} \mathrm{C}$ under a $5 \% \mathrm{CO}_{2}$ atmosphere for 2 days and then exposed to high D-glucose (30 mM; Melone Biomart, Dailan, China) in the presence or absence of fucoidan (Sigma-Aldrich, Shanghai, China; $100 \mu \mathrm{g} / \mathrm{ml}$ ) for a further $24 \mathrm{~h}$. The viability of ARPE-19 cells was determined using a colorimetric MTT assay Sigma-Aldrich) according to a previously described method (3). Absorbance at $550 \mathrm{~nm}$ was determined using the MTP-800 microplate reader. The absorbance at $690 \mathrm{~nm}$ was also measured to compensate for any interfering effects of cell debris and the microtiter plate. The percentage of viable cells was calculated as optical density (OD) of the treated sample/OD of untreated control x $100 \%$.

Lactate dehydrogenase ( $L D H)$ assay. As a result of cytotoxicity, the reduction in the number of viable cells measured using an MTT assay may have been the result of inhibition of cell proliferation or cellular damage, finally leading to cell death. To determine cellular damage, $\mathrm{LDH}$ release into the medium was measured using an LDH assay kit (Sigma-Aldrich). The rate of $\mathrm{LDH}$ release (\%) was expressed as the proportion of $\mathrm{LDH}$ released into the medium compared with the total quantity of LDH present in ARPE-19 cells treated with 2\% Triton X-100 (Sigma-Aldrich). LDH was monitored as the oxidation of reduced nicotinamide adenine dinucleotide (NADH) at $530 \mathrm{~nm}$. The cellular damage (\%) was determined using the equation $\left[\left(\mathrm{OD}_{530}\right.\right.$ of the treated group - $\mathrm{OD}_{530}$ of the control group $) /\left(\mathrm{OD}_{530}\right.$ of the Triton $\mathrm{X}-100$-treated group - $\mathrm{OD}_{530}$ of the control group)] x $100 \%$.

Microscopy imaging of ARPE-19 cells. ARPE-19 cells were seeded at a density of $5 \times 10^{4}$ cells $/ \mathrm{ml}$ in 24 -well plates. Following culturing for 2 days, ARPE-19 cells were exposed to high D-glucose $(30 \mathrm{mM})$ in the presence or absence of fucoidan $(100 \mu \mathrm{g} / \mathrm{ml})$ for another $24 \mathrm{~h}$. The microscopy images were prepared using an automatic microscope (IX70; Olympus, Tokyo, Japan) and a digital CCD camera (Pixera, Los Gatos, CA, USA). ARPE-19 cells were counted and images were captured under a phase-contrast microscope (CX22; Olympus, Tokyo, Japan) in a high-power field (objective lens magnification, $\mathrm{x} 200$ ).

Apoptosis assay. Apoptosis staining was performed using an Annexin V (cell apoptosis signaling component)-fluorescein isothiocyanate-propidium iodide (FITC-PI) apoptosis kit according to the manufacturer's instructions (BioVision, Mountain View, CA, USA). The ARPE-19 cells were grown in a six-well plate at $10^{4}$ cells/well and were pretreated with high glucose $(30 \mathrm{mM})$ in the presence or absence of fucoidan $(100 \mu \mathrm{g} / \mathrm{ml})$. Stained cells were analyzed using FACSCalibur $^{\mathrm{TM}}$ flow cytometer (BD Biosciences, San Jose, CA, USA) with Cell-Quest software (version 1.2, Diva 6.1). A total of 10,000 events were collected for each sample.

Detection of intracellular ROS. Intracellular accumulation of ROS was estimated using the fluorescent dye $\mathrm{H}_{2}$-DCFDA (Sigma-Aldrich), which is converted to a membrane-impermeable and highly fluorescent compound, dichlorofluorescein diacetate (DCF), in the cell in the presence of ROS (13). ARPE-19 cells were exposed to high glucose $(30 \mathrm{mM})$ in the presence or absence of fucoidan $(150 \mu \mathrm{M})$ for $24 \mathrm{~h}$ and were then rinsed with serum-free DMEM/F12 medium and incubated with $5 \mu \mathrm{M} \mathrm{H}_{2}$-DCFDA for $60 \mathrm{~min}$ at $37^{\circ} \mathrm{C}$. The cells were examined under a fluorescence microscope (C1-T-SM; Nikon, Tokyo, Japan). Subsequently, the cells were collected with $0.25 \%$ trypsin and analyzed using a fluorescence spectrophotometer (F-2500; Hitachi, Tokyo, Japan) to detect the fluorescence of DCF inside the cells (excitation wavelength, $488 \mathrm{~nm}$; emission wavelength, $521 \mathrm{~nm}$ ).

Measurement of cytoplasmic $\mathrm{Ca}^{2+}$ influx. $\mathrm{Ca}^{2+}$ imaging was performed as described previously (10). ARPE-19 cells $\left(2 \times 10^{6}\right.$ cells $\left./ \mathrm{ml}\right)$ pre-treated with high glucose $(30 \mathrm{mM})$ for $24 \mathrm{~h}$ in the presence or absence of fucoidan $(100 \mu \mathrm{g} / \mathrm{ml})$ were loaded with calcium-sensitive Fura 2-AM $(1 \mu \mathrm{M})$ in $\mathrm{Ca}^{2+}$-free buffer (Hank's balanced salt solution containing $20 \mathrm{mM}$ HEPES and $1 \%$ bovine serum albumin, $\mathrm{pH} 7.4$; Sigma-Aldrich) for $30 \mathrm{~min}$ at $37^{\circ} \mathrm{C}$ according to the manufacturer's instructions of the Calcium Kit-Fura 2 (Dojindo Laboratories, Kumamoto, Japan). Adenosine triphosphate (ATP; $10 \mu \mathrm{M}$ ) was added directly to the cell suspension after a 3-min baseline recording. Recordings were made using an F-2500 calcium imaging system from FL Solutions (Hitachi, Tokyo, Japan) that calculated the ratio of fluorescent signals obtained at $37^{\circ} \mathrm{C}$ with excitation wavelengths of 340 and $380 \mathrm{~nm}$ and an emission wavelength of $510 \mathrm{~nm}$. The excitation wavelengths at 380 and $340 \mathrm{~nm}$ were used to measure the free Fura- 2 and the $\mathrm{Ca}^{2+}$-bound Fura-2, respectively. The fluorescent activities at $340 / 500 \mathrm{~nm}(\mathrm{~F} 1)$ and of $380 / 500 \mathrm{~nm}(\mathrm{~F} 2)$ as well as the ratio (R) of F1 to F2 were recorded using the spectrophotometer at the indicated times. The $\mathrm{Ca}^{2+}$ concentration $(\mathrm{C})$ was then calculated using the following formula: $\mathrm{C}=224 \mathrm{x} \mathrm{R}$, where 224 is the $\mathrm{Kd}$ number. 
A

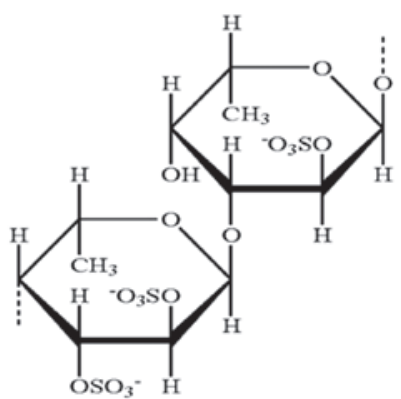

C

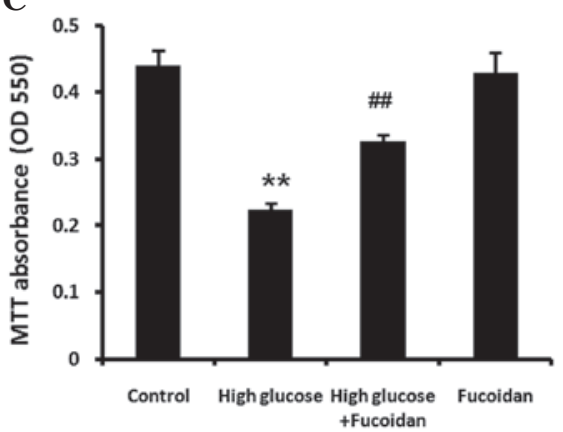

B

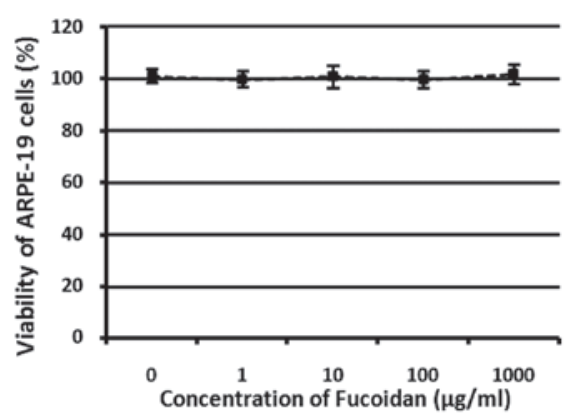

D

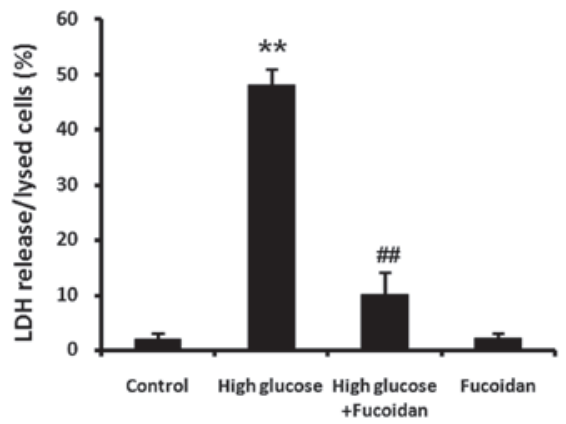

Figure 1. Non-toxic fucoidan protects ARPE-19 cells against high glucose-induced cell death. (A) Chemical structure of fucoidan. (B) ARPE-19 cells were cultured for 2 days and treated with different concentrations of fucoidan $(0,1,10,100$ or $1,000 \mu \mathrm{g} / \mathrm{ml})$ for a further $24 \mathrm{~h}$. Fucoidan induced no cytotoxicity in ARPE-19 cells. (C and D) ARPE-19 cells were cultured for $2 \mathrm{~d}$ and exposed to a high concentration of D-glucose (30 mM) in the presence or absence of fucoidan $(100 \mu \mathrm{g} / \mathrm{ml})$ for another $24 \mathrm{~h}$. An MTT assay and LDH assay were performed. Fucoidan protected ARPE-19 cells from high glucose-induced cell death. Fucoidan treatment alone did not affect the growth of normal ARPE-19 cells. Values are expressed as the mean \pm standard deviation ( $=3$ ). P $<0.05$ was considered to indicate a statistically significant difference. ${ }^{* *} \mathrm{P}<0.01$, high glucose vs. control; ${ }^{\# \#} \mathrm{P}<0.01$, high glucose + fucoidan vs. high glucose. OD, optical density; LDH, lactate dehydrogenase.

Western blot analysis. Electrophoresis was performed using a vertical slab gel with a $12 \%$ polyacrylamide content (Sigma-Aldrich) according to the method described previously (11). Transfer of proteins from the SDS-PAG to a membrane was performed electrophoretically according to the method described previously (12) with certain modifications using a Semi-Dry Electroblotter (Sartorious AG, Göttingen, Germany) for 90 min with an electric current of $15 \mathrm{~V}$. The membrane was treated with Block Ace ${ }^{\mathrm{TM}}$ (4\%; Sigma-Aldrich) for $30 \mathrm{~min}$ at $22^{\circ} \mathrm{C}$. The first reaction was performed using a rabbit polyclonal immunoglobulin ( $\mathrm{Ig}$ ) $\mathrm{G}$ antibody against unmodified protein or against phosphorylated protein of ERK1/2 (100 ng/ml; Proteintech Group, Inc., Chicago, IL, USA) in phosphate-buffered saline containing $0.03 \%$ Tween 20 (Haoranbio Biomart, Shanghai, China) for $1 \mathrm{~h}$ at $22^{\circ} \mathrm{C}$. Following washing in the same buffer, the second reaction was performed using horseradish peroxidase-conjugated anti-rabbit goat $\mathrm{IgG}(20 \mathrm{ng} / \mathrm{ml}$ at proper dilution with 1X Tris-buffered saline and Tween 20; Proteintech Group, Inc.) for $30 \mathrm{~min}$ at $22^{\circ} \mathrm{C}$. Following washing, the enhanced chemiluminescence (ECL) reaction was performed on the membrane using the ECL Plus western blotting detection system $^{\mathrm{TM}}$ (Prime Western Blotting Detection Reagent Kit and Image Quant 400; GE Healthcare, Tokyo, Japan).

Statistical analysis. Values are expressed as the mean \pm standard deviation. Each experiment was repeated at least three times. Student's t-test was used and $\mathrm{P}<0.05$ was considered to indicate a statistically significant difference. Analyses were performed using SPSS version 19.0 (IBM SPSS, Armonk, NY, USA).

\section{Results}

Fucoidan is not cytotoxic to ARPE-19 cells. CellTiter $96^{\circledR}$ AQueous One Solution Cell Proliferation Assay was used to determine the cytotoxicity of fucoidan. At the concentrations used in the present study $(0,1,10,100$ and $1,000 \mu \mathrm{g} / \mathrm{ml})$, fucoidan did not have any marked cytotoxic effect on ARPE-19 cells (Fig. 1B). In subsequent experiments, fucoidan was used at a concentration of $100 \mu \mathrm{g} / \mathrm{ml}$ study to investigate its protective effect against high glucose-induced cell death.

Protective effect of fucoidan against high glucose-induced cell death. To investigate the protective effect of fucoidan on ARPE-19 cells against high glucose-induced cell death, ARPE-19 cells exposed to high D-glucose $(30 \mathrm{mM})$ in the presence or absence of fucoidan $(100 \mu \mathrm{g} / \mathrm{ml})$ for $24 \mathrm{~h}$. The viability of ARPE-19 cells was determined using a colorimetric MTT assay (Fig. 1C). As the reduction in the number of viable cells measured using an MTT assay may be due to inhibition of cell proliferation or cellular damage finally leading to cell death, cellular damage was also assessed by detecting LDH release into the medium using an LDH assay kit (Fig. 1D). Furthermore, ARPE-19 cells were counted and images were captured under a phase-contrast microscope (Fig. 2A and B). The results of the abovementioned assays revealed that ARPE-19 cells underwent apoptosis following treatment with $30 \mathrm{mM}$ glucose $(\mathrm{P}<0.01)$, while the non-toxic fucoidan significantly protected ARPE-19 cells from high glucose-induced cell death $(\mathrm{P}<0.01)$. Fucoidan treatment alone did not affect the growth of normal ARPE-19 cells. 

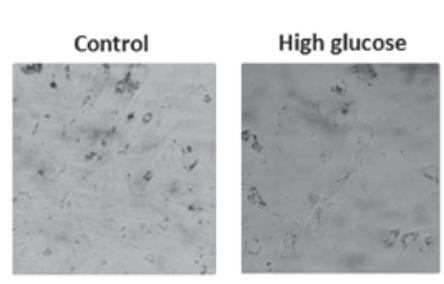

C

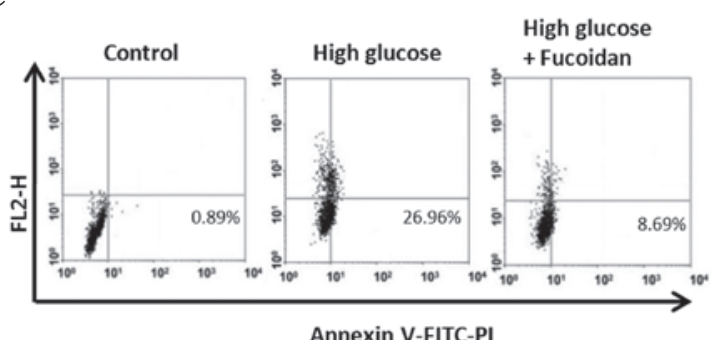

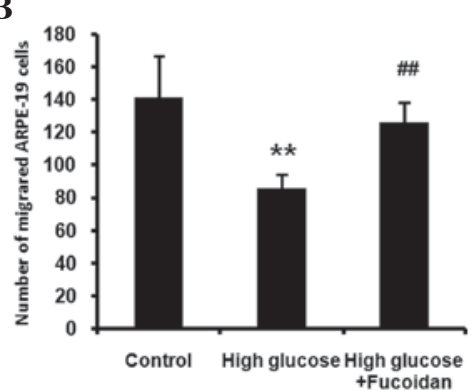

D

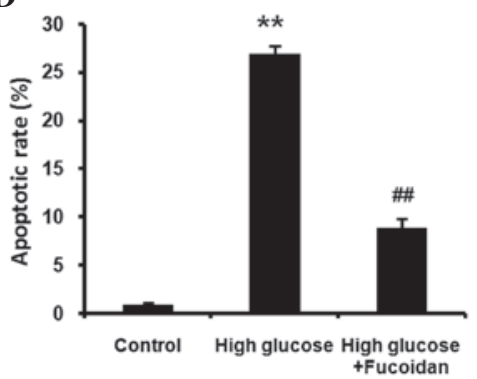

Figure 2. (A) Images of ARPE-19 cells. ARPE-19 cells were counted and images were captured using phase-contrast microscopy in a high-power field (objective lens magnification, x200). ARPE-19 cells died following treatment with high glucose, while fucoidan significantly protected ARPE-19 cells from high glucose-induced cell death. (B) Quantification of A. (C) Inhibitory effect of fucoidan on high glucose-induced apoptosis in ARPE-19 cells. The lower right field represents the apoptotic cells. Cells exposed to high glucose exhibited an increased apoptotic rate compared with that of untreated control cells. Fucoidan significantly reduced the percentage of apoptotic cells. (D) Quantification of C. Values are expressed as the mean \pm standard deviation $(\mathrm{n}=3)$. ${ }^{* *} \mathrm{P}<0.01$, high glucose vs. control; ${ }^{\#} \mathrm{P}<0.01$, high glucose + fucoidan vs. high glucose. FITC-PI, fluorescein isothiocyanate-propidum iodide.

A

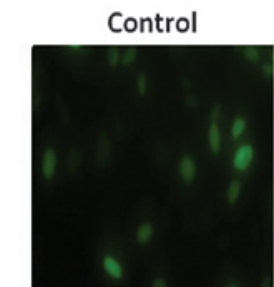

High glucose+Fucoidan

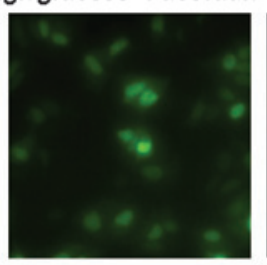

$\mathbf{C}$

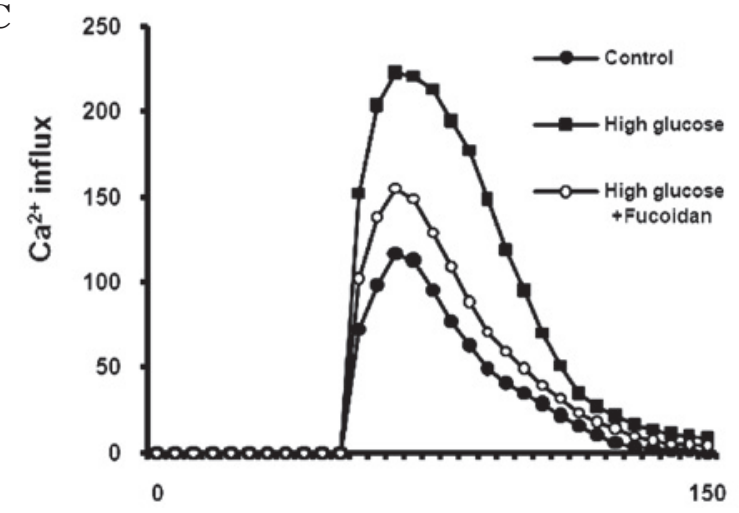

B

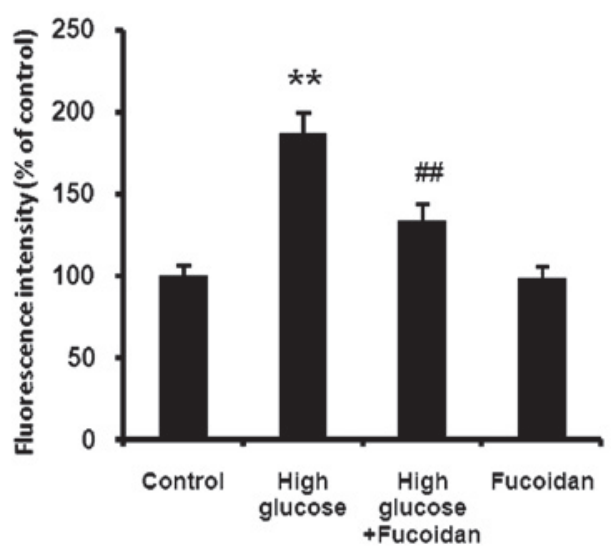

Figure 3. (A) Inhibitory effect of fucoidan on high glucose-induced ROS generation. Intracellular ROS production was increased in high glucose-induced cells relative to that in unexposed control cells. Increases in intracellular ROS generation were abrogated by treatment with fucoidan. Fucoidan treatment alone did not affect the ROS generation in normal ARPE-19 cells. (B) Quantification of A. (C) Fucoidan interferes with $\mathrm{Ca}^{2+}$ influx in response to high glucose. ARPE-19 cells pretreated with $30 \mathrm{mM}$ high glucose in the presence or absence of fucoidan $(100 \mu \mathrm{g} / \mathrm{ml})$ were loaded with Fura 2 -AM $(1 \mu \mathrm{M})$ in Ca ${ }^{2+}$-free buffer. The cells exposed to high glucose exhibited an increase in $\mathrm{Ca}^{2+}$ influx compared with that in untreated control cells. Fucoidan significantly reduced the increased $\mathrm{Ca}^{2+}$ influx. ${ }^{\bullet}$ Control, "High glucose, ${ }^{\circ}$ High glucose + fucoidan. Values are expressed as the mean \pm standard deviation $(\mathrm{n}=3) .{ }^{* *} \mathrm{P}<0.01$, high glucose vs. control; ${ }^{\# \#} \mathrm{P}<0.01$, high glucose $+\mathrm{f}$ ucoidan vs. high glucose. ROS, reactive oxygen species. 

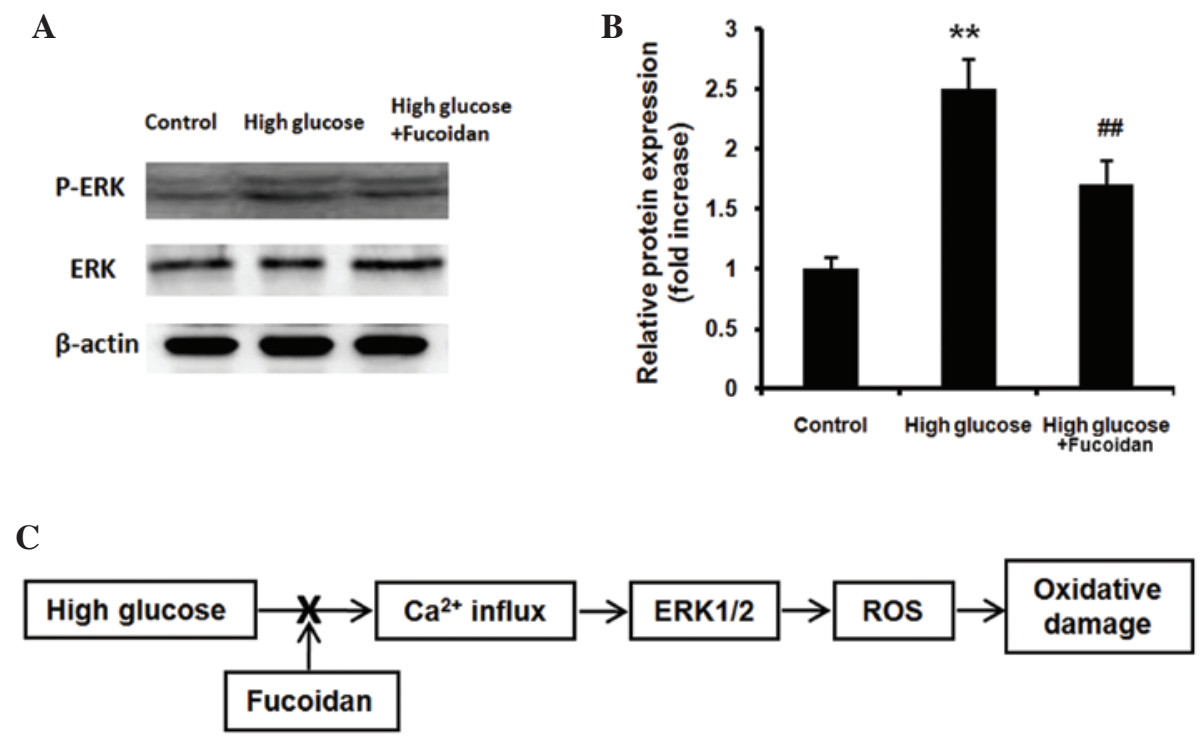

Figure 4. (A) Inhibitory effect of fucoidan on ERK phosphorylation in response to high glucose. ARPE-19 cells were exposed to a high concentration of glucose $(30 \mathrm{mM})$ in the presence or absence of fucoidan $(100 \mu \mathrm{g} / \mathrm{ml})$. High glucose activated phosphorylated ERK1/2, while fucoidan significantly eradicated the ERK phosphorylation induced by high glucose. (B) Quantification of A. (C) Protective mechanism of fucoidan against high glucose-induced oxidative damage. $\mathrm{Ca}^{2+}$ and ERK1/2 are the upstream components activating ROS generation. High glucose increased the generation of ROS in ARPE-19 cells, while fucoidan significantly protected ARPE-19 cells from high glucose-induced oxidative damage via normalization of ROS generation through the $\mathrm{Ca}^{2+}$-dependent ERK1/2 signaling pathway. Values are expressed as the mean \pm standard deviation $(n=3) .{ }^{* *} \mathrm{P}<0.01$, high glucose vs. control; ${ }^{* \#} \mathrm{P}<0.01$, high glucose + fucoidan vs. high glucose. p-ERK, phosphorylated extracellular signal-regulated kinase; ROS, reactive oxygen species.

Fucoidan inhibits high glucose-induced apoptosis in ARPE-19 cells. To examine whether fucoidan protects against high glucose-induced apoptosis, ARPE-19 cells exposed to high glucose $(30 \mathrm{mM})$ in the presence or absence of fucoidan $(100 \mu \mathrm{g} / \mathrm{ml})$ for $24 \mathrm{~h}$. Flow cytometric analysis was used to quantify the apoptotic rate using staining with Annexin V-FITC-PI. The cells exposed to high glucose exhibited an increase in the apoptotic rate compared with that of untreated control cells (Fig. $2 \mathrm{C}$ and $\mathrm{D} ; \mathrm{P}<0.01$ ), while fucoidan significantly reduced the percentage of apoptotic cells $(\mathrm{P}<0.01)$.

Fucoidan inhibits high glucose-induced ROS generation. ARPE-19 cells were exposed to high glucose $(30 \mathrm{mM})$ in the presence or absence of fucoidan $(100 \mu \mathrm{g} / \mathrm{ml})$ for $24 \mathrm{~h}$. Subsequently, the effect of fucoidan on glucose-induced generation of ROS in ARPE-19 cells assessed using $\mathrm{H}_{2}$-DCFDA, a fluorescent ROS indicator. The intracellular ROS generation was increased in high glucose-exposed cells relative to that in unexposed control cells. However, this increase in intracellular ROS was abrogated by treatment with fucoidan (Fig. 3A and B; P<0.01).

Fucoidan inhibits high glucose-mediated $\mathrm{Ca}^{2+}$ influx in ARPE-19 cells. ARPE-19 cells pretreated with high glucose $(30 \mathrm{mM})$ in the presence or absence of fucoidan $(100 \mu \mathrm{g} / \mathrm{ml})$ were loaded with calcium-sensitive Fura 2-AM $(1 \mu \mathrm{M})$ in $\mathrm{Ca}^{2+}$-free buffer and ATP $(10 \mu \mathrm{M})$ was placed directly into the cell suspension after a 3-min baseline recording. The cells exposed to high glucose exhibited an increase in $\mathrm{Ca}^{2+}$ influx compared with untreated control cells. Fucoidan significantly reduced the increased $\mathrm{Ca}^{2+}$ influx (Fig. $3 \mathrm{C}$ ).

Fucoidan inhibits high glucose-mediated ERK phosphorylation. ARPE-19 cells exposed to high glucose $(30 \mathrm{mM})$ in the presence or absence of fucoidan $(100 \mu \mathrm{g} / \mathrm{ml})$ for $24 \mathrm{~h}$. The phosphorylation of ERK1/2 protein was examined using western blot analysis. High glucose increased the levels of activated/phosphorylated ERK1/2 (Fig. 4A and B; P<0.01), while fucoidan significantly reduced the ERK1/2 phosphorylation induced by high glucose $(\mathrm{P}<0.01)$.

\section{Discussion}

The present study demonstrated for the first time, to the best of our knowledge, the beneficial effect of fucoidan on DR, through protecting ARPE-19 cells against high glucose-induced oxidative damage via inhibition of ROS generation through a $\mathrm{Ca}^{2+}$-dependent ERK1/2 signaling pathway. DR is a common complication of DM and is a main cause of loss of vision $(1,2)$. The the loss of vision associated with this disease is caused by oxidative damage inflicted on RPE cells in the presence of high glucose (3). The RPE is a highly specialized retinal cell layer, which has important roles in the regulation and development of photoreceptors in the vertebrate retina (14). RPE cells function in transporting and stocking materials, such as retinaldehyde, and phagocytosing detached photoreceptor outer segments, intercepting light, removing free radicals, synthesizing cytokines and forming the blood-retina barrier (10). The integrity of the RPE is of key importance for maintaining the integrity and proper functioning of the human retina (15).

In previous years, interest in the biological activities of marine organisms has intensified. Fucoidan, from the seaweed Fucus vesiculosus, has been shown to exhibit potent antioxidant activities and has effects on molecular mechanisms involved in cancer and inflammation (8). Fucoidan suppresses various inflammatory cytokines, including interleukin- $1 \beta$, tumor necrosis factor- $\alpha$, interferon- $\gamma$ and cyclooxygenase-2 (9). In the present study, an MTT assay indicated a significant decrease 
in the number of viable ARPE-19 cells following treatment with high glucose. Fucoidan, which was not cytotoxic to ARPE-19 cells, exerted a significant protective effect on ARPE-19 cells against high glucose-mediated toxicity. As the $\mathrm{LDH}$ release data were almost inversely identical to the results of the MTT assay, the glucose-induced toxicity in the present study was not due to an inhibition of cell proliferation, but a result of cellular damage leading to cell death.

A high concentration of glucose induced dysregulation of the electron transport chain activity and caused increased electron slippage, resulting in overproduction of toxic ROS (16). The ROS overproduction contributed to oxidative stress-induced cell injury (4). The vascular and multiorgan complications in DM are associated with high glucose-induced ROS overproduction (17). It has been reported that ROS may mediate RPE cell dysfunction and lead to hyperglycemic complications in diabetes (5), and ROS generation is responsible for cell damage in cultured ARPE-19 cells (6). Therefore, to protect the retina from oxidative damage, it is important to protect RPE cells via preventing intracellular ROS production.

The RPE provides an ideal environment for the accumulation of ROS, which in turn leads to mitochondrial dysfunction and apoptosis $(6,7,18)$. In normal living cells, phosphatidylserine only exists on the cytosolic side of the lipid bilayer of the cell membrane, but in the early phase of cell apoptosis, phosphatidylserine flips to the extracellular side of the membrane. Annexin V, a type of $\mathrm{Ca}^{2+}$-dependent phosphatide-conjugated protein, has a high affinity to and thus binds to phosphatidylserine in early apoptotic cells (19). Therefore, Annexin V was used for detecting apoptosis in the present study, and the results indicated that fucoidan prevented ARPE-19 cells from entering high glucose-induced apoptosis, which was consistent with the results of the MTT and LDH assays.

Consistent with the theories and results presented in the present study, a previous study on ROS generation demonstrated that high glucose led to an increase in ROS generation in ARPE-19 cells (20). The present study reported that fucoidan inhibited the generation of ROS, indicating that fucoidan offers distinct protection against high glucose-induced oxidative damage. To better understand the protective mechanism of fucoidan on ARPE-19 cells, it was investigated whether fucoidan may inhibit high glucose-induced increase of $\mathrm{Ca}^{2+}$ influx in ARPE-19 cells. It was observed that, as an early signaling factor, $\mathrm{Ca}^{2+}$ influx was increased by high glucose in ARPE-19 cells, while fucoidan effectively inhibited the increased $\mathrm{Ca}^{2+}$ influx.

Furthermore, it has been demonstrated that the ERK1/2 pathway includes cytoplasmic $\mathrm{Ca}^{2+}$ influx (21) and the activation of ERK1/2 may be involved in defense signaling against oxidative damage in cells (22). ERK $1 / 2$ is the signaling cascade involved in protection from oxidative damage and its activation is generally hypothesized to mediate cell survival (23). High glucose accelerates the rate of oxidative phosphorylation and eventually causes a change in redox signaling to activate the mitogen-activated protein kinase pathway (24). In the present study, western blot analysis indicated an increase in the expression of phosphorylated ERK1/2 in high glucose-treated ARPE-19 cells, which was inhibited by fucoidan. Changes in the expression of activated ERK1/2 closely reflect cell damage, suggesting that high glucose-induced oxidative damage of ARPE-19 cells was mediated by ERK1/2 activation. This was in agreement with the results on $\mathrm{Ca}^{2+}$ influx, indicating that the $\mathrm{Ca}^{2+}$ influx and ERK1/2 signaling are the upstream components activating ROS generation.

As presented in the schematic in Fig. 4C, fucoidan inhibits high glucose-induced oxidative damage via normalization of ROS generation through the $\mathrm{Ca}^{2+}$-dependent ERK1/2 signaling pathway in ARPE-19 cells. The $\mathrm{Ca}^{2+}$-dependent cascade is a complex process and it has been reported that ROS themselves may lead to transient and rapid activation of ERK (25). Therefore, although the protective effect of fucoidan on ARPE-19 cells against high glucose-induced oxidative damage was demonstrated, the complex underlying mechanism requires further study.

In conclusion, the present study was the first, to the best of our knowledge, to demonstrate that treatment with fucoidan significantly protected ARPE-19 cells from high glucose-induced oxidative damage via inhibition of ROS generation through the $\mathrm{Ca}^{2+}$-dependent ERK1/2 signaling pathway. The activity and mechanism of action of fucoidan are expected to provide important information for the use of biological agents and the development of novel clinical treatments of DR.

\section{References}

1. Wang J, Yang MM, Rong SS, Ng TK, Li YB and Liu XM: Association of paraoxonase gene polymorphisms with diabetic nephropathy and retinopathy. Mol Med Rep 8: 1845-1851, 2013.

2. Lorenzi $\mathrm{M}$ and Gerhardinger C: Early cellular and molecular changes induced by diabetes in the retina. Diabetologia 44: 791-804, 2001.

3. Yuan Z, Feng W, Hong J, Zheng Q, Shuai J and Ge Y: p38MAPK and ERK promote nitric oxide production in cultured human retinal pigmented epithelial cells induced by high concentration glucose. Nitric Oxide 20: 9-15, 2009.

4. Yu T, Robotham JL and Yoon Y: Increased production of reactive oxygen species in hyperglycemic conditions requires dynamic change of mitochondrial morphology. Proc Natl Acad Sci USA 103: 2653-2658, 2006.

5. Yu T, Sheu SS, Robotham JL and Yoon Y: Mitochondrial fission mediates high glucose-induced cell death through elevated production of reactive oxygen species. Cardiovasc Res 79: 341-351, 2008.

6. Winkler BS, Boulton ME, Gottsch JD and Sternberg P: Oxidative damage and age-related macular degeneration. Mol Vis 5: 32, 1999.

7. Cai J, Nelson KC, Wu M, Sternberg P Jr, Jones DP, et al: Oxidative stress and protection of the RPE. Prog Retin Eye Res 19: 205-221, 2000.

8. Myers SP, O'Connor J, Fitton JH, Brooks L, Rolfe M, Connellan P, Wohlmuth H, Cheras PA and Morris C: A combined Phase I and II open-label study on the immunomodulatory effects of seaweed extract nutrient complex. Biologics 5: 45-60, 2011.

9. Li C, Gao Y, Xing Y, Zhu H, Shen J and Tian J: Fucoidan, a sulfated polysaccharide from brown algae, against myocardial ischemia-reperfusion injury in rats via regulating the inflammation response. Food Chem Toxicol 49: 2090-2095, 2011.

10. Nishiura H, Tokita K, Li Y, Harada K, Woodruff TM, Taylor SM, Nsiama TK, Nishino $\mathrm{N}$ and Yamamoto T: The role of the ribosomal protein S19 C-terminus in Gi protein-dependent alternative activation of p38 MAP kinase via the C5a receptor in HMC-1 cells. Apoptosis 15: 966-981, 2010.

11. Laemmli UK: Cleavage of structural proteins during the assembly of the head of bacteriophage T4. Nature 227: 680-685, 1970. 
12. Kyhse-Andersen J: Electroblotting of multiple gels: a simple apparatus without buffer tank for rapid transfer of proteins from polyacrylamide to nitrocellulose. J Biochem Biophys Methods 10: 203-209, 1984.

13. Rastogi RP, Singh SP, Häder DP and Sinha RP: Detection of reactive oxygen species (ROS) by the oxidant-sensing probe 2 ',7'-dichlorodihydrofluorescein diacetate in the cyanobacterium Anabaena variabilis PCC 793. Biochem Biophys Res Commun 397: 603-607, 2010.

14. Jackson GR, Owsley C and Curcio CA: Photoreceptor degeneration and dysfunction in aging and age-related maculopathy. Ageing Res Rev 1: 381-396, 2002.

15. Zarbin MA: Age-related macular degeneration: review of pathogenesis. Eur J Ophthalmol 8: 199-206, 1998.

16. Allen DA, Yaqoob MM and Harwood SM: Mechanisms of high glucose-induced apoptosis and its relationship to diabetic complications. J Nutr Biochem 16: 705-713, 2005.

17. Brownlee M: Biochemistry and molecular cell biology of diabetic complications. Nature 414: 813-820, 2001.

18. Giddabasappa A, Bauler M, Yepuru M, Chaum E, Dalton JT and Eswaraka J: $17-\beta$ estradiol protects ARPE-19 cells from oxidative stress through estrogen receptor- $\beta$, Invest. Ophthalmol Vis Sci 51: 5278-5287, 2010.

19. Lee JE, Lee RA, Kim KH and Lee JH: Induction of apoptosis with diallyl disulfide in AGS gastric cancer cell line. J Korean Surg Soc 81: 85-95, 2011.
20. Dong X, Li Z, Wang W, Zhang W, Liu S and Zhang X: Protective effect of canolol from oxidative stress-induced cell damage in ARPE-19 cells via an ERK mediated antioxidative pathway. Mol Vis 17: 2040-2048, 2011.

21. Castro R, Sun XH, Liu XB, Martinez JR and Zhang GH: Inhibition of $\mathrm{Ca}^{2+}$ influx by surfactant in NR8383 alveolar macrophages. Inflamm Res 57: 489-496, 2008.

22. Glotin AL, Calipel A, Brossas JY, Faussat AM, Tréton J and Mascarelli F: Sustained versus transient ERK1/2 signaling underlies the antiand proapoptotic effects of oxidative stress in human RPE cells, Invest. Ophthalmol Vis Sci 47: 4614-4623, 2006.

23. Guillonneau X, Régnier-Ricard F, Dupuis C, Courtois Y and Mascarelli F: Paracrine effects of phosphorylated and excreted FGF1 by retinal pigmented epithelial cells. Growth Factors 15: 95-112, 1998

24. Cai L: Suppression of nitrative damage by metallothionein in diabetic heart contributes to the prevention of cardiomyopathy. Free Radic Biol Med 41: 851-861, 2006.

25. Qin S, McLaughlin AP and De Vries GW: Protection of RPE cells from oxidative injury by 15 -deoxy-delta12,14-prostaglandin J2 by augmenting GSH and activating MAPK. Invest Ophthalmol Vis Sci 47: 5098-5105, 2006 